\title{
Capítulo 2. \\ Elementos de una antropología del cuidado
}

Z ste capítulo tiene varios apartados. El primero gravita en torUno a la influencia de los griegos y romanos en la edificación de la propuesta foucaultiana de una ética del cuidado; en el segundo apartado, los esfuerzos se concentran en exponer los factores claves para la edificación de una antropología del cuidado, a saber: la alteridad, el tiempo y el ejercicio del pensamiento; en un último apartado, el investigador Cubides Cipagauta nos presenta los aspectos constitutivos de los individuos como sujetos morales, desde un estudio de Michel Foucault, teniendo como derrotero de reflexión la ética del cuidado.

\section{La ética del cuidado: raíces en los griegos y en los romanos}

La propuesta ética de Foucault tiene raíces en los pensadores griegos y romanos. Para el francés, la educación debe abrir un espacio para la creatividad, la estética y la ética. La enseñanza es vital y evocativa del pensamiento, por lo cual resulta muy importante ir más allá de la educación como forma política de mantener el statu quo y utilizarla contra los poderes hegemónicos. 
Para Foucault, el escenario educativo se erige en un espacio ideal para promover la ética del cuidado, práctica que en occidente se remonta a la época grecorromana, según lo demuestra el mismo autor:

Ahora bien, en mis cursos en el Colegio de Francia he intentado captar este problema a través de lo que podría denominarse una práctica de sí mismo que es, a mi juicio, un fenómeno bastante importante en nuestras sociedades desde la época greco-romana - pese a que no haya sido estudiado-. Estas prácticas de sí mismo han tenido en la civilización griega y romana una importancia, y sobre todo una autonomía, mucho mayores de lo que tuvieron posteriormente cuando se vieron asumidas, en parte, por instituciones religiosas, pedagógicas, de tipo médico y psiquiátrico. (Foucault, 2016)

Foucault reconoce que la reflexión sobre el cuidado viene de tiempos muy antiguos, pues en su pesquisa logró determinar que autores como Epicteto y Marco Aurelio no ahorraron esfuerzos a la hora de disertar sobre el cuidado. Asimismo, el pensador francés arguye que a finales del siglo XX muchos pensaban que ese tema era de dudosa procedencia y que el pensar sobre el cuidado de sí mismo se había terminado equiparando con un nuevo narcicismo, según lo afirma Foucault:

Es interesante ver cómo en nuestras sociedades, por el contrario, el cuidado de uno mismo se ha convertido, a partir de un cierto momento - y es muy difícil saber exactamente desde cuándoen algo un tanto sospechoso. Ocuparse de uno mismo ha sido, a partir de un determinado momento, denunciado casi espontáneamente como una forma de egoísmo o de interés individual en contradicción con el interés que es necesario prestar a los otros o con el necesario sacrificio de uno mismo. (Foucault, 2016) 
Según Foucault, para los griegos y los romanos tener una vida recta donde uno pueda autodeterminarse implicaba ocuparse de sí, cuidar de sí y a la par conocerse muy bien; afirmación que nos ayudaría a comprender un poco más la frase de Sócrates en el oráculo de Delfos: "Conócete a ti mismo". De esta manera, conocerse a sí permite al ser humano superarse a sí mismo y alcanzar el control de los apetitos, los impulsos y las pasiones:

Existió entonces toda una ética que ha girado en torno al cuidado de sí y que proporciona a la ética clásica su forma tan particular. No pretendo afirmar con esto que la ética sea el cuidado de sí, sino que, en la Antigüedad, la ética, en tanto que práctica reflexiva de la libertad, ha girado en torno a este imperativo fundamental: "cuida de ti mismo". (Foucault, 2016)

Resulta clave entender que para los griegos una ética del cuidado involucra un conocimiento de sí mismo y de sus congéneres, conocimiento que implica cuidarse y ayudar a cuidar a los otros, de manera tal que si no hay un conocimiento de los otros, de sus condiciones, de sus problemas, de sus carencias de salud, la comprensión resulta insuficiente.

En este apartado cabe realizar un alto y exponer algunos de los elementos característicos de la Grecia Clásica y de la Humanitas romana, que sirvieron de insumo a Foucault para apoyar sus disertaciones teóricas en torno al cuidado.

\section{- Concepción antropológica de los griegos y los romanos}

La sociedad griega se caracterizó por ser una sociedad de guerreros y, como tal, en esta había una convicción en torno al caballero, quien debía ser un buen orador y un buen luchador, capaz de hablar con elocuencia, pero con conciencia de sumisión a los designios del mandatario de turno. Los griegos usaron como acicate teórico de sus enseñanzas los textos de Homero, por lo cual es comprensible que los niños recitaran 
de memoria los poemas homéricos, los cuales, a su vez, promovían una moral anclada en el heroísmo, donde la valentía y el honor se constituían en los valores más altos por conquistar. Aquiles, Héctor, Áyax, Néstor, Patroclo, Agamenón y Ulises son los grandes héroes griegos, y el carácter de todos ellos fue esculpido bajo el código de honor y valentía que se impartía desde la educación. El individuo de la educación homérica vive en función de alcanzar un ideal y la gloria; esta es el reconocimiento y el premio último de ese ideal. Gracias a su excelencia los caballeros eran reconocidos y su memoria perduraba en el tiempo por la fama y el honor logrado. Por el contrario, los que no lograban el reconocimiento, estaban relegados al ostracismo del olvido: "Otra característica de la virtud (areté) homérica es el amor propio, por el cual cada uno aspira a realizar en sí mismo la virtud más alta" (Rojas Osorio, 2010, p. 4).

\section{- La educación en la retórica y la sofística}

Algunos de los maestros más destacados de retórica fueron los sofistas ${ }^{1}$ Georgias de Leontini (485-380 a. C.), Hipias de Elis (segunda mitad del siglo V a. C.) y Protágoras de Abdera (480410 a. C.). Estos sofistas educaban en virtudes, enseñanza que consistía en formar para ejercer el arte de hablar bien (con elocuencia), el arte de escribir bien (gramática), el arte de argüir bien (dialéctica) y el arte del lenguaje métrico (la poesía). Para los sofistas estas virtudes eran muy relevantes, no obstante, priorizaban sobre todas ellas la elocuencia. Haciendo uso

1 El término sofista, del griego sophía (бофía), "sabiduría” y sophós (бофóৎ), "sabio", es el nombre dado en la Grecia Antigua, a quien tenía como profesión enseñar la sabiduría. Dicho calificativo se le acuñó tiempo después a los individuos que hacían uso de su "inteligencia práctica". Platón los criticó porque utilizaban trampas dialécticas, con el objetivo de enseñar la virtud. 
de la retórica ellos lograron acaparar la atención y cautivar a las multitudes.

En relación con la retórica, Rojas Osorio afirma que:

Es una formación de razonamiento, que conlleva una investigación científica del lenguaje y de esa investigación nace la gramática. El máximo encomio de la retórica lo hallamos en el sofista Georgias de Leontini. Para él el discurso es un poder. (Rojas Osorio, 2010, p. 9)

Con la elocuencia y las demás virtudes ellos educaron a los futuros políticos. Protágoras de Abdera consideraba que la educación auténtica radicaba en desarrollar actitudes para ejercer la política, la cual consideraba un arte. Occidente debe a los sofistas el origen del trivium (gramática, retórica y dialéctica) y de igual forma el origen del quadrivium (aritmética, geometría, astronomía y música) inicialmente promovido por Hipias de Elis.

\section{- La educación de la clase gobernante: Platón}

Platón ${ }^{2}$ desarrolló su visión educativa a la par con su filosofía política y es en su principal obra de tinte político, La Repúbli$c a$, donde el pensador ateniense expuso su plataforma educativa, la cual no está centrada en todo el mundo, sino en dos clases puntuales: los guardianes y los sabios regentes. Platón hace de entrada explicita su tesis: los sabios son los llamados a gobernar, con el fin de que culminen todas las calamidades de la tierra. Platón identifica tres clases sociales: la clase de los

2 Platón ('el de anchas espaldas'), cuyo nombre de pila fue Aristocles nació en Atenas en el 427 a. C. y falleció en el 342 a. C. Fue discípulo de Sócrates durante veinte años, hasta la muerte de su maestro. Fundó la Academia, en la que se profundizaba en matemáticas, ciencias y filosofía (dialéctica). En esta época redactó sus famosos Diálogos. Su alumno más destacado fue Aristóteles. 
artesanos, cuya tarea es producir todo lo que demanda la sociedad; la clase guerrera (los guardianes) que tienen como función defender la ciudad y la clase gobernante, cuyo objetivo es administrar la polis.

En la formación educativa Platón se preocupó mucho por la clase gobernante, poco por la clase guerrera y casi nada por la clase de los artesanos. Los guardianes debían ser educados en música, gimnasia y matemáticas (aritmética, geometría y astronomía). Platón creía que todos los ciudadanos debían participar, si así se requiriese, en la defensa de la ciudad y por ello todos debían recibir entrenamiento militar. Según, Rojas Osorio (2010), Platón en las leyes propone que: "la educación sea para todos, incluso la educación militar para los jóvenes de ambos sexos. El currículo general incluirá además literatura, música y matemáticas" (p. 17).

Para Platón la filosofía es muy importante, porque gracias a ella se puede superar el mundo de las sombras sensibles y se puede acceder al mundo inteligible o mundo de las ideas. Y solo se enseñará filosofía a la clase gobernante, con el fin de darle una vida nueva, una vida de sabiduría a la civilización griega. Finalmente, podemos aseverar que la educación propuesta por Platón no es para nada democrática, sino más bien aristocrática, se concentra en la formación de los guardianes, pero principalmente, de los gobernantes. La educación que propone Platón defiende un Estado doctrinal, que dictamina lo que es verdadero y lo que es falso, lo que se debe enseñar y lo que no. 


\section{- Aristóteles ${ }^{3}$ y la educación moral}

El estagirita nos dice que existen dos clases de virtudes: las virtudes intelectuales y las virtudes morales. De las primeras afirma que su origen radica en la enseñanza, y son indispensables para desarrollar la experiencia y el tiempo; de las segundas, que proceden de la costumbre (Aristóteles, 2015, p. 48). Por la misma línea, plantea Aristóteles que al niño se le educa moralmente por intermedio de la costumbre y sin necesidad de dar argumentos. Ya adulto, el niño, gracias al uso de la razón, descubrirá por sí solo los motivos de la educación moral que le dieron sus padres. La familia se convierte entonces en la responsable de la educación moral y de la formación de buenos hábitos, acordes a las costumbres de su comunidad concreta. Para el fundador del Liceo, la relevancia de la formación de hábitos es vital, pues sin ella no se puede alcanzar la virtud; y si no se desarrolla la virtud, aparece su antagónico que es el vicio, realidad que perjudicará notablemente a la comunidad.

\section{- Los epicúreos y los escépticos}

Epicuro $^{4}$ de Samos, a diferencia del pensamiento comunitarista de Aristóteles, defiende la necesidad de educar para sí mismo, y no necesariamente para la polis; en otras palabras, el verdadero telos educativo debe estar encaminado a la realización personal. La ataraxia o serenidad se logra mediante el conocimiento de la naturaleza propia y debe ser la finalidad

3 Aristóteles (384-322 a. C.). Nació en Estagira, en Macedonia. Estudió durante veinte años en la Academia de Platón, en Atenas, donde después fundó el Liceo, donde tuvo como discípulo al distinguido Alejandro Magno.

4 Epicuro de Samos (341-270 a. C.). Su escuela se denominó El Fardín y estuvo abierta a todo el que quisiera practicar la sabiduría, incluyendo a las mujeres. De su producción intelectual se conservan algunas epístolas: la Carta a Heródoto, Carta a Meneceo y Carta a Pítocles. 
principal de la práctica educativa. Epicuro concibe la filosofía como el arte de vivir, y la ética como el cuidado de sí. Si se filosofa todo el tiempo, sencillamente se está procurando el cuidado de sí. Otro de los elementos importantes para Epicuro es la amistad, virtud que no solo implica la relación con el otro, sino consigo mismo.

Por otra parte, los escépticos ${ }^{5}$ optaron en sus disertaciones por la tranquilidad del alma y prefirieron no comprometerse con la incertidumbre de no poseer la verdad, es así como no creen las verdades objetivas, al considerarlas "imposibles", puesto que el sujeto es el encargado de enjuiciar la realidad y él es susceptible a la equivocación. Los escépticos promovieron una práctica educativa anclada en la libertad interior, en vivir tranquilamente, en la indagación de la realidad y en la serenidad del alma o ataraxia. Las concepciones antropológicas clásicas, con excepción de los epicúreos y de los escépticos, coinciden en defender un ideal del hombre como un 'animal social', un individuo que debe formarse en aras de la polis, de la sociedad. Ahora bien, esa formación tenía como ejes centrales, preparar guerreros y buenos oradores; de ahí la importancia que le dan a la elocuencia como es el caso de los sofistas. Platón comparte la idea de formar para defender la ciudad, pero se preocupa sobremanera por la clase gobernante. Por su parte, Aristóteles matiza la idea de formar en hábitos, para desarrollar virtudes, que a la postre van a favorecer el desarrollo de la polis. Las corrientes que se separaron de este ideal, como los epicúreos, hicieron hincapié

5 El escepticismo es una corriente filosófica basada en la duda, representada en la escuela de Skeptikoi, de cuyos seguidores se decía que "no afirmaban nada, solo opinaban”. Es así como la palabra escéptico proviene del griego skeptikoi (de skeptesthai que en griego significa examinar), el nombre dado a los seguidores del filósofo griego Pirrón. El significado de esta palabra indica "quien duda e investiga". 
en que la educación debería estar encaminada a la realización personal, más que en prepararse para defender la polis. Asimismo, los escépticos se inclinaron por promover reflexiones educativas, donde el principal telos guarda directa relación con la búsqueda de la tranquilidad del alma y la libertad interior; aspectos que Foucault va a tener en cuenta para edificar su propuesta de la ética del cuidado.

\section{- Humanitas: la educación romana}

La formación denominada paideia en Grecia pasa a llamarse en Roma Humanitas 6 . La humanitas romana incluye dentro de su definición el desarrollo moral del individuo. Asimismo, $h u^{-}$ manitas implica también conocimiento y perfeccionamiento del sujeto humano. Dentro de la concepción antropológica ideal de la humanitas se encuentra como pilar de la misma la honestidad, que le apuntaba al humano íntegro caracterizado por ser justo, virtuoso, honrado y cumplidor de sus deberes. La filosofía que ayuda a la humanitas se constituye en sabiduría, la cual es requerida para lograr el buen vivir. Sócrates, Platón y Aristóteles concibían la retórica y la filosofía como ciencias separadas, mientras que los romanos abogaban por su unión. Es así como Cicerón ${ }^{7}$ exigía que el orador soportara su formación en la filosofía, la historia y el derecho. La educación del

6 Humanitas es un término del latín que designa "Humanidad". Dentro de los romanos guardaba estrecha relación con la cultura, educación y pedagogía propias del hombre libre y con las cuales están relacionadas todas las disciplinas. El individuo que logra la Humanitas alcanza las cualidades que hacen al hombre un ser verdaderamente humano, que lo alimentan con una cultura y lo diferencian notablemente del bárbaro.

7 Marco Tulio Cicerón (106-43 a. C.). Nació en Arpino (Italia), se educó en Roma, donde estudió retórica, jurisprudencia y filosofía griega. Fue senador por dos años y después fue asesinado. 
individuo se hacía con el objetivo de formar buenos ciudadanos capaces de actuar en favor de su patria. En la humanitas se identificaba el papel mediador del maestro, aunque no se les reconocía en su merecimiento; realidad que obligaba siempre a buscar esclavos o libertos para que desempeñaran el oficio de ser pedagogos. Esa formación del hombre completo requería de una enseñanza elemental, donde se incluían componentes de "gramática, cultura general, letras, música, geometría, aritmética y astronomía. Los estudios superiores pertenecían a la escuela de la retórica, que coronaba la educación del hombre completo" (Rojas Osorio, 2010, pág. 43).

\section{- El estoicismo ${ }^{8}$ en la educación romana}

El estoicismo fue la filosofía de mayor influencia en los dos primeros siglos del Imperio romano. Uno de los pensadores latinos seguidor de esta tradición fue Séneca ${ }^{9}$. Séneca, a diferencia de otros autores, enfatiza en la voluntad como elemento clave de la formación. Al saber dominar las pasiones, el individuo puede ejercer el gobierno de mí mismo, aspecto indispensable para poder llevar más adelante una vejez con tranquilidad y disfrute sosegado de la vida. Para Séneca la humanitas se desarrolla dentro de comunidades culturales, donde es preciso integrarse a una red de amistades. Asimismo, la filosofia se desarrolla en el escenario institucional creado para la humanitas que es la escuela, donde es preciso llevar una existencia comunitaria.

8 El término proviene del lugar que Zenon de Citio escogió para sus encuentros en una Stóa poililé, es decir, 'pórtico pintado', palabra de la que deriva estoicismo. Esta escuela (s. IV a. C.) concibe que el ideal del sabio es la serenidad y la independencia del mundo externo.

9 Lucio Anneo Séneca nació en el año 4 de nuestra era en Córdoba, España. En el año 12 viajó a Roma y estudió oratoria y filosofía. Llegó a ser senador y cónsul. Fue maestro de Nerón. Se suicidó en el año 65. 
Otro de los estoicos latinos destacados fue Epicteto ${ }^{10}$ quien afirma que la libertad del alma radica en la virtud, y que el vicio por antonomasia representa la esclavitud. El rol fundamental de la filosofía es ayudar a los individuos a ser libres, o lo que es lo mismo, hombres virtuosos.

Por otra parte, Cicerón habla de "artes liberales", concepción educativa que equivale entre los griegos a la paideia, donde se agruparon los siete conocimientos que ellos consideraron más relevantes, y que más tarde se constituirían en la metodología medieval con el trivium (gramática, retórica y dialéctica), y el quadrivium (música, aritmética, geometría y la astronomía). Entre todas estas artes, fue la retórica la que cautivó más a los romanos, y en la cual profundizaron más. El texto obligado para la educación literaria fue la Eneida, de Virgilio, el cual se convirtió en el libro latino escolar por excelencia.

Los filósofos no defendían la retórica sino la sabiduría, el cuidado de sí y el cuidado del otro, aspectos que fueron asumidos por Foucault y que se cristalizaron en su propuesta por alcanzar la autonomía. Varios de los factores expuestos por los griegos y los romanos le van a servir como prolegómenos para disertar sobre el cuidado y sus implicaciones; factores como la alteridad, el tiempo, la voluntad, la reflexión serán claves en la propuesta de Foucault.

10 Epicteto nació en Hierápolis, Frigia (50-138). Era hijo de esclavo, al ser liberado se fue a Roma y se dedicó al estudio de la filosofía. 


\section{Factores importantes de una antropología del cuidado}

La alteridad, el tiempo y el uso del intelecto son algunos factores que aportan significativamente a que el ser humano se cuide a sí mismo y a sus congéneres. El hombre no es una rueda suelta, hace parte de todo un entramado social, se constituye en el seno de una sociedad, esto evidencia el hecho de que necesitamos de los otros para fraguarnos como personas; en la propuesta antropológica del cuidado, este tópico es fundamental. Igualmente, el tiempo se erige como un factor supremamente importante a la hora de implementar la epimeleia heautou, sin este componente no es posible el cuidado; y, finalmente, se encuentra el pensamiento como un elemento relevante en el momento de centrar la atención en el cuidado: Si actuamos precipitadamente, sin cavilar, sin indagar sobre las condiciones del entorno se pueden desencadenar consecuencias nefastas para la salud y para la vida misma. Estos tres elementos serán el eje de reflexión en las siguientes líneas.

\section{La alteridad: factor constituyente de una ética del cuidado}

La ética del cuidado defendida por Foucault es de doble vía: Por un lado, implica el cuidado propio, y por el otro, el cuidado del alter ego. Sin embargo, es matizada en el hecho de que es difícil ayudar a los demás, si primero no he cuidado de mi propio ser. Es muy cierto esto, no solo porque carecería de autoridad moral para exigir cuidado, si no he cuidado de mi propia persona, como también, porque es ilógico cuidar a otros si mi estado no es el mejor, y si mis condiciones, mis fuerzas están a punto de desfallecer como lo manifiesta en el mismo Foucault. El ethos implica también una relación con los otros, en la medida en que el cuidado de sí convierte a quien lo posee en alguien capaz de ocupar en la ciudad, en la comunidad, o en las relaciones interindividuales, 
el lugar que conviene - ya sea para ejercer una magistratura o para establecer relaciones de amistad-. En este mismo sentido, el cuidado de sí implica también una relación con el otro en la medida en que, para ocuparse bien de sí, es preciso escuchar las lecciones de un maestro. Uno tiene necesidad de una guía, de un consejero, de un amigo, de alguien que le ayude a descubrir la verdad. De este modo, el problema de las relaciones con los demás está presente a lo largo de todo este desarrollo del cuidado de sí (Foucault, 2016).

En el anterior fragmento, Foucault trae a colación otro elemento muy importante a la hora de promover un estilo de vida alrededor del cuidado, y tiene que ver con la alteridad. El "otro" es necesario en mi vida, no solo para que yo lo cuide, sino para que me guie en mi propio cuidado. El otro puede ser mi maestro en las artes cuidadoras. Para Foucault, el ser humano que se ocupa del cuidado propio y de los otros adopta la posición de filósofo, pues piensa que gracias al cuidado, la sociedad puede marchar bien, con gente dispuesta y con ganas de hacer que las cosas funcionen, por lo cual afirma: "no se trata de hacer pasar el cuidado de los otros a un primer plano anteponiéndolo al cuidado de sí; el cuidado de sí es éticamente lo primero, en la medida en que la relación a uno mismo es ontológicamente la primera" (Foucault, 2016).

Ahora bien, en una sociedad excluyente como la nuestra, y donde en algunos sectores de la población se presentan exterminios masivos, desplazamientos forzados, genocidios, etnocidios y persecuciones violentas urge promover una convivencia sana, donde se aprenda a respetar, sin distinción de sexo, raza, religión, cultura, y donde el diálogo, la tolerancia y el reconocimiento del otro en tanto otro, sean prioridades. En este sentido, las diferentes formas de discriminación deben ser motivo de reflexión y de acción, puesto que van en detrimento de la vida de otros, del bienestar de muchos que no piensan como nosotros, pero que tienen todo el derecho a disentir. 
Resulta importante reconocer que el otro es quien termina definiéndome, determinándome, pues es gracias a la interacción con él como me apropio de elementos esenciales para el desarrollo humano como el lenguaje, la cultura, las normas. Por lo mismo, es gracias a los otros que me apropio del mundo y lo lleno de significado. El otro me objetiva, pero yo también puedo objetivarlo a él, pues es gracias a la existencia que se posibilita la reciprocidad, como por ejemplo, en el caso de la vergüenza "que es por naturaleza, reconocimiento. Reconozco que soy como el prójimo me ve" (Sartre, 1954, p. 143).

Ahora bien, no solo frente al otro me avergüenzo, sino que es gracias a él que me puedo captar completamente en todas las estructuras que me definen, puesto que el otro coadyuva en la definición de mi identidad como persona, al no ser este otro un ente inerme, que no me afecta en nada, sino que, por el contrario, me complementa:

Practico entonces una especie de solipsismo de hecho; los otros son esas formas que pasan por la calle, esos objetos mágicos capaces de actuar a distancia, sobre los cuales puedo obrar por medio de determinadas conductas. Poco o nada me cuido de ellos; actúo como si estuviera solo en el mundo; rozo "a la gente" como rozo las paredes, los evito como evito los obstáculos, su libertad-objeto no es para mí sino su "coeficiente de adversidad"; ni siquiera imagino que puedan mirarme. (Sartre, 1954, p. 236)

Aunque muchas veces aflore en nosotros una especie de espíritu misántropo ${ }^{11}$ y ondeemos las banderas del odio a la humanidad,

11 Misantropía, del griego $\mu$ í $\sigma \omega$ (miso): "yo odio", y áv $\theta \rho \omega \pi$ o (anthropos): "hombre, ser humano"). La misantropía se caracteriza por ser una actitud social de rechazo, odio y hostilidad hacia el género humano. La actitud contraria es la filantropía, donde se manifiesta un amor hacia el género humano. Los misántropos son personas que muestran claramente un deseo de 
es incorrecto obviar a los otros, puesto que cada uno de ellos tiene una identidad, una historia, una individualidad, que ayuda a la construcción de sentido de la humanidad y del sentido identitario propio.

Soy poseído por el prójimo; la mirada ajena modela mi cuerpo en su desnudez, lo hace nacer, lo esculpe, lo produce como es, lo ve como yo no lo veré jamás. El prójimo guarda un secreto: el secreto de lo que soy. Me hace ser y, por eso mismo, me posee, y esta posesión no es nada más que la conciencia de poseerme. (Sartre, 1954, p. 226)

Una antropología del cuidado es aquella donde el individuo procura abordar la alteridad, promoviendo la inclusión, la diversidad, la interculturalidad, el pluralismo y denunciando la exclusión social, sexual, racial y política que oprime a una gran cantidad de personas y las deja al borde del ostracismo. Una antropología del cuidado busca fraguar la ética de la comprensión, el reconocimiento de la diferencia y el diálogo, con el fin de encontrar puntos de convergencia para limar cualquier aspereza que desencadene un episodio de violencia.

$\mathrm{Al}$ apostar por el cuidado, los individuos procuran ser empáticos intentando ponerse en los zapatos del otro, descubriendo la intencionalidad en sus actuaciones, preguntándose por el significado y los diversos sentidos que están detrás de esas conductas que muchas veces desconciertan. Igualmente, la comprensión se constituye en el vehículo indispensable de cualquier intento de diálogo y de construcción de perspectivas comunes. Los individuos manejan relaciones horizontales, donde tratan a los otros como iguales sin imponer nada, ni intimidar a nadie, y donde se busca propiciar

inconformidad hacia los otros. Esta actitud puede ser leve o fuerte y puede ir desde la crítica social hasta el uso de la violencia. 
espacios de solución de conflictos, procurando que las diferencias no se traduzcan en el exterminio del contrario, sino en valoración y reconocimiento efectivo de su existencia y de sus derechos.

Aterrizando la propuesta del cuidado en el contexto colombiano se debe procurar que sea pluricultural y multiétnica, donde se relacionen e interactúen los diferentes grupos sociales como el blanco, el negro, el mestizo, el amerindio y el afroamericano, y se construyan espacios de encuentro y de concertación con el fin de afianzar la unidad y la promoción del respeto por las diferencias y la identidad nacional. En un país como el nuestro, que lleva más de seis décadas con un conflicto armado fratricida, la promoción de la alteridad resulta fundamental, puesto que solo nos podemos constituir como individuos en relación con los demás. Ahora bien, es necesario ser consciente de que dicha relación no pretende ser un remanso de paz, sino que, por el contrario, muchas veces es tensa, difícil y en algunos casos hasta violenta. Una antropología del cuidado reconocerá la anterior situación, puesto que al ser conscientes de que los seres humanos somos por naturaleza complejos y conflictivos, urge aunar esfuerzos desde la familia, el colegio y la sociedad en general, para llegar a acuerdos por medio del diálogo, de manera tal que se propicien espacios de concertación donde emerjan esas dificultades y se puedan dirimir las diferencias.

Nuestra propuesta es que la educación, en los diferentes escenarios formales e informales, tenga como asidero antropológico el ideal de un individuo como persona que cultiva la reflexión, la tolerancia, la responsabilidad y el crecimiento mutuo; escenarios donde el colectivo esté por encima de intereses mezquinos particulares y donde el tronco basilar radique en el cuidado. Un cuidado que implique conocimiento de sí mismo, del entorno y de los otros, es decir alteridad. Una sociedad basada en la concepción antropológica del cuidado esculpirá personas solidarias, sensibles, responsables, tolerantes y generosas. 
Si se sigue promoviendo una sociedad y una formación educativa anclada en la competencia, en los estándares y en la "realización" económica, se seguirá promoviendo la dominación, la exclusión, la pobreza, la brecha social entre los que pueden consumir y los que carecen de lo necesario; en cambio, si se promueve una sociedad basada en el cuidado, y se educa desde el cuidado, para el cuidado, los individuos serán más cooperativos, trabajarán en la construcción de horizontes de comprensión y en proyectos sociales que busquen minimizar la pobreza, la enfermedad, el analfabetismo, y, en general, que propendan por el bienestar colectivo.

Los individuos dentro de una sociedad que tiene como asidero el cuidado dejarán de ser indiferentes e indolentes, y se preocuparán por los otros, no solo los familiares, sino también, los desconocidos y por aquellos que, muchas veces, hasta resultan incómodos. Quien comprenda esta propuesta y la asuma se constituirá en agente activo de la transformación del contexto, y sujeto en la solución a tantas dificultades sociales.

Una propuesta antropológica soportada en el cuidado producirá un cambio en la mentalidad consumista e irresponsable de los individuos y los hará más conscientes del papel protagónico que deben jugar a la hora de cultivar una vida humanista, humanizante e incluyente, al asumir responsabilidades consigo mismos, con los demás y con el cuidado del planeta. En esta nueva concepción antropológica, las personas se reconocen como sujetos pensantes, sociales, instintivos y culturales, y la razón se constituye en el faro que ilumina las acciones, sin descuidar en ningún momento, la afectividad, los instintos y el contexto de los individuos.

Una sociedad y una educación que enfatiza en el cuidado como su arteria principal no corre el riesgo de caer en un narcicismo moderno, puesto que el cuidado implica necesariamente la reciprocidad y la alteridad; puesto que el cuidado involucra entre otros factores, el ejercicio dialógico constante, la trasformación de la inequidad, la tolerancia, no como el acto de "soportar" 
al otro, sino como un ejercicio empático de intentar entender al otro desde su situación, y no solo desde mis intereses. Formar en el cuidado es trabajar por la unidad, respetando la diversidad y la heterogeneidad, pues, al formar en el cuidado, se suscita la eclosión de la reciprocidad, la alteridad, la empatía y el respeto por el pensamiento de los otros.

Se trata de la alteridad entendida, no como un simple soportar al otro, porque "toca", o porque así lo manda la ley, sino en el sentido de que el otro me interpela, suscita mi interés y mi crecimiento como persona; una alteridad como constitución de mi individualidad y como preludio a la sociedad. Una alteridad soportada en el respeto al otro, en el alter ego, donde la interacción social se funde en una relación más horizontal, dialogante, y donde no se imponga nada, sino que se converse, se confronten posturas, se concilie, y se busquen salidas.

Esta nueva propuesta anclada en el cuidado busca fraguar una ética de la comprensión y del reconocimiento, donde se fomente la argumentación en vez de la excomulgación y la exclusión, donde se demuestre, y no se imponga, donde no haya cabida al dogmatismo ni a la represión, sino que prime el respeto mutuo. Donde se trate al otro como un igual, puesto que solo a un igual se le sustentan las ideas con razones, mientras que a un inferior se le ordena, se le impone y se le intimida. En esta línea, a un superior se le suplica o se le pide, se le solicita o se le trata de seducir. Demostrar solo se da entre iguales, de manera tal que solo tratando al otro como igual, el discurso mismo de la demostración implica que siempre se tenga en cuenta su punto de vista, o como decía Kant, que seamos capaces de tener en cuenta el pensamiento de los otros.

Para concluir este apartado, se puede afirmar que la alteridad es una de las columnas principales de la antropología del cuidado, puesto que nuestra vida sin la presencia de los otros se tornaría en una mentira, o un ideal falso. Es gracias a la alteridad que podemos combatir la segregación, el exterminio de grupos, la xenofobia, y 
logramos comprender que el otro me complementa, coadyuva en la constitución de mi identidad como individuo social. Reconocer al otro como factor constitutivo de mi mundo, me posibilita solucionar las diferencias que emergen gracias a nuestra naturaleza conflictiva, las cuales, al no ser superadas, desencadenarían episodios de violencia e intolerancia.

\section{El tiempo: segundo factor importante en una antropología del cuidado}

Cuando un hombre se cuida como es debido y sabe a qué cosas debe temer y lo que debe esperar, asume su vida con cautela y puede orientar su hogar, evitando al máximo caer en el error; al respecto escribe Foucault:

El que cuida de sí hasta el punto de saber exactamente cuáles son sus deberes como señor de la casa, como esposo o como padre será también capaz de mantener con su mujer y sus hijos la relación debida. (Foucault, 2016)

Asimismo, si se atiende el imperativo socrático de conocerse a sí mismo, los individuos abordarían con más inteligencia fenómenos de dominación, que se desprenden de cualquier vertiente ideológica, política, económica, sexual, institucional, religiosa, que solo buscan en determinado momento esclavizarnos y mantenernos como en un letargo sin fin.

Para Foucault, si seguimos las directrices socráticas de conocernos, podemos corregir nuestros rumbos errados, purificarnos, transformarnos y hasta llegar a edificar nuestra propia salvación. 
Foucault considera que la premisa griega la epimeleia heautou ${ }^{12}$, el cuidado de sí, no es sino una exhortación a volcar la atención hacia uno mismo y saber en qué consisten los cuidados que se desprenden producto de ese vuelco de la atención:

En cuanto a los epicúreos, la Carta a Meneceo se abría al principio de que la filosofia debía considerarse como ejercicio permanente del cuidado de uno mismo. "Que nadie, siendo joven, tarde en filosofar, ni siendo viejo se canse de la filosofía. Pues no es para nadie ni demasiado pronto ni demasiado tarde para asegurar la salud del alma”. (Foucault, 1987, p. 44)

Foucault considera que parte del cuidado que se debe tener consigo mismo guarda relación con el descanso, la lectura para cultivar el intelecto, la composición literaria para cultivar la imaginación, y la actividad física, para evitar enfermedades que se deriven del descuido del cuerpo. Asimismo, Foucault considera que nunca es tarde para ocuparse de sí mismo, puesto que esta es una tarea permanente:

"No hay pues edad para ocuparse de uno mismo. No es nunca ni demasiado pronto ni demasiado tarde para ocuparse de la propia alma", decía ya Epicuro: "Aquel que dice que el tiempo de filosofar no ha llegado todavía o que ha pasado ya es semejante a aquel que dice que el tiempo de la felicidad no ha llegado todavía o que ya no existe". (Foucault, 1987, p. 47)

12 Es el término con el que los griegos designaban "el cuidado de sí", la inquietud de sí mismo, el hecho de sacar tiempo para reflexionar sobre sí mismo, su vida, su realidad, su salud. Foucault lo retoma y realiza una serie de escritos teniendo como eje de reflexión esta palabra griega. Dentro de la Epimeleia, Sócrates destacaba el hecho de cuidar la razón, la verdad y el alma, antes que cualquier bien material y era enfático al recomendar el ocuparse de sí mismos, para ocupárselo cual, se requiere invertir tiempo. 
En este sentido, se puede abordar el concepto de epimeleia heautou como tarea intermitente, que envuelve no solo preocupaciones, sino todo un maremágnum de ocupaciones, que van desde el cuidado de los padres para con sus hijos, de los hijos para con sus padres, de los jefes para con sus empleados y del cuidado que se le debe brindar a un limitado físico o mental, a un herido o a un enfermo. Tanto los cuidados para con los otros como el cuidado propio, implican un trabajo que, a su vez, demanda tiempo y sacrificio. En relación con el factor tiempo se trae a colación a la escritora Comins Mingol ${ }^{13}$, quien realiza unas precisiones en torno a este factor fundamental a la hora de hablar de epimeleia. El cuidado, entonces, es un oficio de toda la vida, para preservar la vida y no cualquier clase de vida, sino una vida digna de ser vivida, con salud, compañía - ojalá de sus seres queridos-, y con una pluralidad de sentidos.

La sociedad neoliberal nos ha vendido la idea que todo aquello que no genere dividendos es pérdida de tiempo. Contemplamos así, que mucha gente está ocupada y preocupada por realizar cosas que generen ganancias, sin importar el gusto, la satisfacción personal; a este proyecto que muchas veces implica ganar dinero a toda costa, se le invierten todas las energías, y se terminan sacrificando otros aspectos fundamentales de la vida, como la salud, el hogar y la felicidad.

El estrés, la sensación de escasez de tiempo. Cada vez más individuos se percatan de que el mundo acelerado en el que vivimos

13 Irene Comins Mingol es docente investigadora del área de Filosofía de la Universitat Jaume I de Castellón y codirectora del Máster Universitario Internacional en Estudios de Paz, Conflictos y Desarrollo de la misma Universidad. Entre sus escritos cabe mencionar los siguientes: La ética del cuidado y la construcción de la paz (Icaria, 2008) y Filosofía del cuidar: una propuesta coeducativa para la paz (Icaria, 2009). 
no solo no le conduce a ninguna parte, sino que, además, es generador de frustración, de depresión e infelicidad. El movimiento Slow es el más representativo al respecto, se trata ya de un movimiento global a favor de una nueva forma de concebir los tiempos (Comins Mingol, 2009, p. 163).

Afortunadamente, en el mundo ha surgido una especie de movimiento que intenta hacerle contrapeso a la ideología del fast, donde hay pobreza de tiempo, donde todo hay que realizarlo a grandes velocidades, y muchas veces sin reparar acerca de su bondad, puesto que lo relevante es que se entregue a tiempo. Ese afán cunde nuestra cotidianidad y nos satura, nos enferma, nos agobia, nos deprime. Este movimiento guarda relación y contrasta con el slowly, a saber: lo lento, lo pausado, lo que da espacio para que maduren las cosas, y para que fluyan las situaciones. Hace ya un tiempo se viene trabajando en Europa este movimiento que busca ofrecer alternativas a este mundo caótico, rápido, violento e inhumano. Inicialmente, se está promoviendo dicho movimiento en dos ámbitos bien determinados, el educativo (Slowly Education) y el alimenticio (Slowly Food):

Valores tales como la tranquilidad, bonanza, calma, orden, sosiego, serenidad, templanza, persistencia, paciencia e incluso paz, tienen que ver con la ausencia de estrés, con la ausencia de prisa, con dedicar suficiente tiempo a las cosas. Violencia, agresión, nerviosismo, irritabilidad parecen más vinculados a la falta de dedicación de tiempo a las cosas. (Comins Mingol, 2009, p. 165)

Adicionalmente, el tiempo es un elemento relevante a la hora de emprender labores relacionadas con el cuidado propio y el de los demás: "El factor tiempo es imprescindible a la hora de hablar de tareas de atención y cuidado, estas requieren paciencia, tranquilidad, reposo; valores que parecen estar pasados de moda cada vez más" (Comins Mingol, 2009, p. 143). 
Para nuestro cuidado y el de los otros se requiere de ocio, pero el ocio no es un no hacer nada, es un tiempo para recargar baterías, para reflexionar sobre nuestro presente y nuestro porvenir, para entablar amistades, para preservar la familia, para realizar nuestros hobbies, estudiar, escuchar música, ir a cine, realizar una actividad física. El ocio es necesario y no es una pérdida de tiempo, ni mucho menos de dinero, por la sencilla razón de que si no tenemos tiempo para cuidarnos, para estar sanos, lo tendremos que tener para estar enfermos, postrados en una cama y con el desgaste de energías que esto genera, además del tiempo y del dinero que se debe invertir. $\mathrm{Al}$ respecto afirma Mingol:

Necesitamos tiempo para pensar en los otros, en los que sufren, en los silenciados. Nuestras vidas ocupadas, ajetreadas y nuestros horarios repletos de actividades no nos acercan a las auténticas necesidades de los seres humanos en otros lugares, más bien nos aleja de esa realidad y nos aliena en un diminuto, aunque aparentemente inmenso universo ególatra [...] igualmente requerimos de tiempo para pensar, para hablar, para participar en nuestra comunidad. En definitiva, para construir una cultura de la paz. (Comins Mingol, 2009, pp. 168-169).

Desde el mercado laboral competitivo a escala mundial se sataniza el ocio y se promueve su negación, o sea, el negocio. En el negocio se impulsa el individualismo, el éxito a toda costa, se descuidan la familia, los amigos y hasta la propia integridad, toda a cambio de un placer efimero y en algunos casos hasta pueril. En el negocio, el ser humano se olvida del descanso, sacrifica sus fines de semana, busca todo el tiempo estar ocupado, frases como: el tiempo es oro o el tiempo perdido lo lloran los santos, son refranes populares que refuerzan la idea de que hay que estar produciendo a toda hora. Frente a esta mentalidad es necesario tener en cuenta las palabras de Mingol: 
No solo necesitamos más tiempo para el cuidado en las familias y en nuestro entorno, también aquellas profesiones que tienen el cuidado como razón de ser deben repensar el papel del factor tiempo como elemento determinante de un cuidado de calidad. Este es el caso de la sanidad y los diversos servicios de atención social como guarderías o residencias. (Comins Mingol, 2009, p. 157)

Ahora bien, es preciso matizar un poco en el anterior aspecto que tiene relación con la salud. El afán, el lucro particular y rápido, el estrés cunden como una especie de pandemia en todas las profesiones, y las relacionadas con la salud no quedan exentas de esta enfermedad. La salud, en vez de ser un servicio, se ha convertido en un negocio, un fortín para llenar las arcas de unos pocos, un foco de corrupción, un espacio ideado para que emerja thánatos. Es así como los servicios de salud en la actualidad, son pésimos, y en vez de aportar a la salud de los pacientes, contribuyen con su deterioro, (citas médicas que se convierten en una carrera contrarreloj, médicos que deben atender gran cantidad de pacientes en el menor tiempo posible, para finalmente, recomendar reposo, y medicamentos al menor costo). Las citas con especialistas se dilatan y pueden tardar varios meses, y se ha vuelto pan de cada día, ver morir personas a las entradas de los hospitales o clínicas, porque no hay sistemas de salud humanos que velen adecuadamente por la salud de las personas. En Colombia tenemos un sistema de salud sin recursos, en el que los profesionales son mal remunerados, y deben tener hasta tres trabajos para poder vivir holgadamente.

Por otra parte, algunos profesionales, con sus planes "de mejor servicio de calidad" en vez de incluir terminan excluyendo y ampliando la brecha de la desigualdad social, puesto que la venta de planes de salud prepagada, - que dista mucho de los servicios de salud de calidad para todos_- y con la excusa de la atención prioritaria y urgente, confirma que la salud no es un derecho, sino un 
lujo que se puede ofrecer y al que solo pueden acceder quienes tienen los medios para adquirirla.

Resulta apremiante, desde la ética del cuidado, que los profesionales de la salud sean bien remunerados, que se establezcan tiempos adecuados para la atención a los pacientes, que haya equipos modernos y los medicamentos necesarios para una atención de calidad, que se promueva la cultura de la prevención y del cuidado mutuo, y que desde la academia se prepare a los futuros profesionales para ejercer humanamente la profesión, de manera tal que el médico sea auténticamente humano y en su desempeño profesional vaya más allá de los diagnósticos.

Desde otro ángulo, a nivel familiar, urge enfatizar en la importancia de rescatar los espacios de encuentro comunes, como las comidas, las salidas colectivas y los festejos:

Recuperar los momentos de comida para tener tiempo de hablar y cuidar anímicamente unos de otros. No dejemos por ejemplo que la televisión nos robe esos momentos [...] se trata de reivindicar el acto social del comer que se remonta a la sagrada cena. (Comins Mingol, 2009, p. 161)

Se trata entonces de alcanzar una formación integral, donde, desde la academia se puede trabajar en campañas de concientización sobre el uso adecuado del tiempo y, en el mismo, incluir la importancia del cuidado; es preciso reforzar la idea de que el ocio no es perdedera de tiempo, sino inversión en uno mismo y en los demás:

Sería necesaria una educación en el valor del cuidado, para que fuese observado el dedicarle tiempo como algo positivo y no como una pérdida de tiempo. Para replantear las prioridades: si es mejor trabajar más horas para consumir más o trabajar menos horas para cuidar más. En general es necesario educar en el valor del tiempo de interacción, del tiempo social, en el que convivimos con los otros. Entre muchas cosas que podemos 
compartir se encuentra la comida. No es accidental que la palabra compañero derive de las palabras latinas que significan con pan. (Comins Mingol, 2009, p. 162)

En este sentido, es imperioso matizar el hecho de que el ocio es necesario no solo para el cuidado, sino también para la comunicación, la interacción social, para fomentar la sociabilidad, la alteridad, la empatía, la convivencia, valores tan relevantes que ayudarán a evitar la eliminación del otro y la imposición del reinado del egoísmo y la incertidumbre. El tiempo es necesario para nuestra capacidad comunicativa, detener la velocidad, pues dedicar tiempo necesario, es la base del diálogo, pero no solo para que lo escuchen, sino también para saber escuchar, con el interés de comprender al otro y ponerse en su lugar. Al respecto, fuente del auténtico diálogo no es el amigo de prisas o a toda hora con estrés, pues cuando dialogamos con prisas tratamos al otro como un medio, tristemente no escuchamos sus palabras, realidad que asegura el camino para la incomprensión y la aparición del conflicto y muchas veces de la violencia. En últimas, el tiempo es la clave fundamental que avala una escucha de calidad, sincera, centrada en el otro y no solo en sí mismo, pues una buena actitud de escucha hace que el otro se sienta tenido en cuenta, importante y valorado.

Ahora bien, el tiempo también es necesario para pensar, para reflexionar, es tal vez por eso, que en muchos lugares no solo a nivel laboral, sino también educativo, nos saturan con tareas muchas veces inoficiosas, impidiendo que se tenga el tiempo para pensar, para alzar nuestra voz en contra de muchas situaciones injustas y opresoras: "Una concepción del tiempo distendida es importante para nuestra actitud moral y para nuestra capacidad de diálogo, pero también para la reflexión crítica. La reflexión crítica necesita reposo, tiempo y dedicación" (Comins Mingol, 2009, p. 167).

El negocio reprime la libertad, esclaviza, mientras que el ocio posibilita volver sobre los actos, reflexionar, dialogar, y abre la posibilidad 
de desarrollar al máximo nuestras potencialidades. Con el aprovechamiento del tiempo libre, se aprende a vivir, a disfrutar del aquí y del ahora. En el negocio, las cosas son cuadriculadas, vienen impuestas y configuradas, hay que hacer tal cosa, para que nos dé tal otra; en el devenir del ocio emerge el disfrute, se goza el instante, se busca la plenitud. En el negocio se busca ganar siempre, la ecuación en el ocio apunta al cooperativismo, al ganar todos, gano mi tiempo, el cual es más pleno en tanto lo comparto con los otros. El ocio abre el espacio a la creatividad, se dispara el genio, el artista, el original. En el negocio se busca homogeneizar, en el ocio se respeta la autonomía y la individualidad.

Es preciso aclarar que no se trata de satanizar el mundo de los negocios, sino de concientizar sobre el descuido que genera en los individuos el hecho de desear obtener dinero a toda costa. Al negar el ocio se sacrifican la familia, los amigos y el bienestar propio. Los negocios bien manejados deben posibilitar que las personas disfruten del dinero que se ha adquirido honestamente, y que no se inmolen por conseguir dinero, que muchas veces no se podrá utilizar para vivir humanamente.

Los dueños de los diferentes negocios también deben ser conscientes de que se deben propiciar espacios de encuentro con el otro y de relajación, en los que la imaginación fluya y donde las máquinas sean utilizadas para el buen desarrollo de las actividades profesionales, no para oprimir e intimidar a los operarios, ni para atosigar con citas y reuniones desgastantes, que en muchos casos resultan infructuosas.

Dejando a un lado las disertaciones de la pensadora española Irene Comins, y retomando a Foucault, cabe enfatizar que para el francés, el tiempo también es un elemento primordial a la hora de promover la epimeleia. Según este pensador, se debe reservar un tiempo diario, en cualquier jornada, para emplearlo en la meditación, en el examen de lo realizado y en el ejercicio de la memoria: 
Se puede, por la noche o por la mañana, reservar algunos momentos al recogimiento, al examen de lo que tiene uno que hacer, a la memorización de ciertos principios útiles, al examen de la jornada transcurrida; el examen matinal y vesperal de los pitagóricos vuelve a encontrarse, con contenidos diferentes sin duda, entre los estoicos; Séneca, Epicteto, Marco Aurelio hacen referencia a esos momentos que deben dedicarse a volverse sobre uno mismo. Se puede también interrumpir de vez en cuando las actividades ordinarias y hacer uno de esos retiros que Musonio, entre tantos otros, recomendaba vivamente: permiten estar a solas con uno mismo, recoger el propio pasado, colocar ante la vista el conjunto de la vida transcurrida, familiarizarse, por la lectura, con los preceptos y los ejemplos de que deseamos inspirarnos, y volver a encontrar, gracias a una vida despojada, los principios esenciales de una conducta racional. (Foucault, 1987, pp. 49-50)

Foucault considera que al dedicar tiempo para el recogimiento, el ser humano puede reencontrarse con los principios rectores de una vida virtuosa, racional y buena, donde la existencia sea más amena y el ser humano se pueda conocer, cumpliendo así la tarea de la frase socrática que reposaba en el oráculo de Delfos, Conócete a ti mismo.

Ahora bien, algunos podrían pensar que dedicar tiempo para la posesión de sí mismo es un desperdicio de tiempo por no estar produciendo, que es una pérdida de dinero, y esto porque se ha relacionado el tiempo con el producir; sin embargo, esta es una equivocación, puesto que el tiempo que se invierte en el cuidado de sí, se traduce en bienestar, armonía y enriquecimiento personal, tópico que no se puede pagar con ningún dinero. Por el contrario, si nos descuidamos en nuestra salud y los medios de sana recreación, debemos pagar a un alto costo las consecuencias del 
cansancio, que repercute en la pérdida de la salud. De esta manera, si se trata de dinero, al cuidarnos, estamos ahorrando una fortuna.

En este sentido, invertir tiempo en nosotros mismos, según Foucault, es la oportunidad para realizar diferentes acciones encaminadas a crecer en calidad de vida:

Están los cuidados del cuerpo, los regímenes de salud, los ejercicios físicos sin exceso, la satisfacción tan mesurada como sea posible de las necesidades. Están las meditaciones, las lecturas, las notas que se toman de libros o de las conversaciones escuchadas, y que se releen más tarde, la rememoración de las verdades que se saben ya pero que hay que apropiarse aún mejor. (Foucault, 1987, p. 52)

Otras de las actividades sugeridas en el concepto de epimeleia están relacionadas con el retirarse a lugares apartados del bullicio, y así poder dedicarse a la contemplación, la oración, y el ayuno. Estos retiros se constituyen en valiosas oportunidades para detectar falencias en nuestro actuar, y pensar la manera de superar estas debilidades en favor de la interacción social; espacios propicios para dialogar con líderes espirituales, o dedicarse a lecturas formativas, en aras del crecimiento espiritual. En últimas, son oportunidades para trabajar aspectos relacionados con el carácter, como la paciencia y la tolerancia, a la vez que valiosísimas oportunidades para el afianzamiento de las virtudes:

La inquietud se dirige sobre todo al punto de paso de las agitaciones y de las perturbaciones, teniendo en cuenta el hecho de que conviene corregir el alma si se quiere que el cuerpo no la domine y rectificar el cuerpo si se quiere que ella conserve el completo dominio de sí misma. (Foucault, 1987, p. 56)

En la adolescencia, el cuidado de sí puede detenerse en la actividad física, en favor del fortalecimiento corporal, mientras que en la edad adulta el cuidado de sí, no se centrará tanto en la actividad 
fisica, sino en detectar amenazas que atenten contra la fragilidad del cuerpo al encontrarse un tanto minado de dolencias y el paso de los años:

El cuerpo del que ha de ocuparse el adulto, cuando se preocupa de sí mismo no es ya el cuerpo joven que se trataba de formar por medio de la gimnasia; es un cuerpo frágil, amenazado, minado de pequeñas miserias y que a su vez amenaza al alma menos por sus exigencias demasiado vigorosas que por sus propias debilidades. (Foucault, 1987, p. 56)

En la práctica, el concepto epimeleia heautou, lleva al ser humano a descubrir las partes que deben intervenirse o ser corregidas, con el fin de evitar ciertos trastornos que pueden llevar a un mayor deterioro de la salud, puesto que cuando tomamos tiempo para examinarnos, concluimos que necesitamos saber en qué estado nos encontramos y, si es pertinente, recibir asistencia, medicación o algún procedimiento quirúrgico: “...cada uno debe descubrir que está en estado de necesidad, que le es necesario recibir medicación y asistencia" (Foucault, 1987, p. 57).

Para Foucault, las enfermedades corporales se pueden detectar gracias a diferentes factores externos, como el pulso, la temperatura corporal, los colores de la cara, los dolores que se manifiestan en diferentes lugares del cuerpo, — como en la cabeza-, pero las enfermedades del alma suelen ser más dificiles de detectar, dado que muchos de sus síntomas pasan desapercibidos al ojo humano; por ello, es necesario estar muy atentos para descubrirlas e intervenirlas inmediatamente, sin dar cabida a que se cuelen en nuestro proceder diario. Al respecto escribe Foucault: "Lo grave, en las enfermedades del alma, es que pasan inadvertidas, o incluso que se las puede tomar por virtudes (la ira por valentía, la pasión amorosa por amistad, la envidia por emulación, la cobardía por prudencia)" (Foucault, 1987, p. 57). 
Ejercitar el pensamiento: tercer factor clave en el desarrollo de una antropología del cuidado

El cuidado de sí también requiere que nos detengamos en el pensamiento mismo, con el fin de examinar, controlar y seleccionar los mejores pensamientos que, a la postre, servirán como soporte para llevar a cabo nuestras actuaciones.

Más que un ejercicio hecho a intervalos regulares, es una actitud constante la que hay que adoptar respecto de uno mismo. Para caracterizar esta actitud, Epicteto emplea unas metáforas que tendrán un largo destino en la espiritualidad cristiana; pero allí tomarán valores bien diferentes. Pide que uno adopte consigo mismo el papel y la postura de un "vigilante nocturno" que verifica las entradas a las puertas de las ciudades o de las casas; o también sugiere que uno ejerza sobre sí mismo las funciones de un "verificador de la moneda", de un "argirónomo", de uno de esos cambistas de dinero que no aceptan ninguna moneda sin haberse asegurado de lo que vale. (Foucault, 1987, p. 62)

Aquí cabe traer a colación también, a propósito del pensamiento, la propuesta kantiana del Sapere Aude, o lo que es lo mismo, el atreverse a pensar por sí mismo.

Kant afirma que la educación tiene tres partes, todas ellas muy importantes: la asistencia o cuidado físico, la disciplina e instrucción, y la formación (bildung). La tarea de la disciplina consiste en domesticar la animalidad del ser humano, puesto que para Kant el hombre es la única criatura que tiene que ser educada, y que gracias a la educación puede alcanzar la perfección de la naturaleza humana.

Kant enfatiza mucho en la disciplina y en el trabajo. A diferencia de Erasmo de Rotterdam, Kant no comulga con la diversión y el juego dentro de la escuela, sino que considera que la escuela 
es el espacio ideal para fomentar la disciplina y el trabajo. Para el pensador de Konisberg, la educación implica disciplina, para superar la animalidad y cultivar las habilidades humanas. Por intermedio de la educación, el ser humano logrará adaptarse mejor a la sociedad humana y moralizarse, es decir, escoger fines buenos, fines que todo el mundo pueda aceptar.

Por otra parte, Kant no está de acuerdo con el ataque que le hacen a la memoria los renacentistas, sino que, por el contrario, descubre que es necesario educar la memoria, al igual que al entendimiento; sabiendo que el entendimiento se educa mediante la práctica de las reglas. Sin embargo, insiste en que es preciso entender las reglas y no solo aplicarlas por inercia. Lo mejor que afirma Kant en torno al cultivo del entendimiento es la referencia a que el individuo piense por sí mismo. El famoso Sapere Aude (atreverse a pensar por sí mismo), es clave en toda la mentalidad ilustrada; y el recto entendimiento se prepara aprendiendo a distinguir las meras opiniones y creencias del auténtico saber.

Kant promueve un pensar por sí mismo, libre de prejuicios, sobre la base de una demostración, y no de un criterio externo de autoridad. Y es que el pensamiento gradualmente ha llevado al conocimiento profundo de la realidad, y a modificar algunas cosas que se consideraban como verdaderas sin antes pasar por el tamiz de la razón. La segunda premisa que expone Kant en relación con el pensamiento, es pensar en el lugar del otro, es decir, aceptar y ponerse en el punto de vista del otro y seguir las consecuencias que de ese punto de vista se desprenden; es mirar el pensamiento del otro, empáticamente, saber por qué razona de esa manera, y no de otra, conocer su cuadro familiar, social y cultural, antes de lanzar juicios a priori. La tercera premisa que expone Kant consiste en ser consecuente con lo que se piensa. Esto implica que si las consecuencias necesarias de una tesis que nosotros sostenemos son insostenibles o contradictorias, debemos abandonar la tesis. Esto es supremamente difícil, puesto que es muy triste y doloroso 
abandonar una convicción que muy frecuentemente está cargada de afectos, y en la que hemos comprometido gran parte de nuestra vida. Ser consecuente es algo fundamental para un verdadero pensamiento, para avanzar en el conocimiento y en la promoción de una antropología del cuidado, donde los individuos se piensen antes de actuar y procuren ser empáticos en sus actuaciones.

En una antropología del cuidado se debe propender porque la persona adquiera autonomía, y no se deje llevar por cualquiera que le fije criterios del cómo vivir. De esta manera, la verdadera educación debe hacer a la persona un ser pensante, que critique, debata, refute cuando no le parezca, fomente la discusión, y sepa dirimir los conflictos que se le originan en la interacción social, puesto que solo así se evita caer en el egocentrismo y la estrechez de pensamiento.

La erradicación de los conflictos y la consecución de la convivencia no es una meta fácil, para lo cual es preciso construir un espacio social y legal en el cual los conflictos puedan manifestarse y desarrollarse sin que la oposición conduzca a la supresión del otro destruyéndolo, o reduciéndolo al silencio o a la impotencia. En una antropología del cuidado se reconoce que cada individuo es diferente, que cada cual tiene su propia manera de pensar, y que tanto su individualidad como su forma de pensar merecen el respeto debido.

El pensamiento se constituye como uno de los principales elementos de una antropología del cuidado, puesto que permite que, como fruto de la reflexión, los individuos vislumbren nuevos caminos, a la vez que les brinda métodos alternativos a los tradicionales, ayudando a buscar nuevos sentidos. Cuando las personas hacen buen uso del intelecto estudian, analizan y sintetizan.

La propuesta de una antropología del cuidado pretende a la par de estimular el pensamiento, suscitar la creatividad, la capacidad de análisis, el sentido crítico y la autonomía. Se busca entonces crear conciencia sobre la responsabilidad propia en la 
conservación de la vida de los congéneres. Al mismo tiempo, al tener como asidero el pensamiento, una antropología del cuidado busca propiciar un espacio donde confluyen la crítica, el debate, la confrontación, el diálogo, el conflicto, y, por supuesto, el compromiso con la transformación de las inequidades y la marginación. Por otro lado, si se realiza un ejercicio consciente de reflexión, la desidia, el desinterés y la indiferencia no visitarán las huestes del corazón asimismo, si se realiza un examen de los pensamientos y de las acciones para corregir lo que se tiene que corregir, la vida fluirá de la mejor manera posible.

El cuidado de sí también es entendido por Foucault como una ética del dominio de sí, donde se procura limitar los placeres para poder dominarse uno mismo, y en relación con los otros:

La reflexión sobre el uso de los placeres que estaba tan directamente ligada a la estrecha correlación entre los tres dominios (sobre uno mismo, sobre la casa y sobre los demás) se encontrará modificada en el transcurso mismo de esa elaboración. ¿Crecimiento de las constricciones públicas y de las prohibiciones? ¿Repliegue individualista que acompaña a la valorización de la vida privada? Hay que pensar más bien en una crisis del sujeto o más bien de la subjetivación: en una dificultad en la manera en que el individuo puede constituirse como sujeto moral de sus conductas, y en unos esfuerzos por encontrar en la aplicación a sí mismo lo que pueda permitirle someterse a unas reglas y dar una finalidad a su existencia. (Foucault, 1987, p. 93)

Al practicar epimeleia heautou el individuo necesariamente desemboca en una vida más saludable, placentera, armoniosa, y donde hay cabida al alter ego. Evocando el tema del reconocimiento del otro, para Foucault, la epimeleia no es un descuidar a los demás, sino una preparación para buscar encuentros, donde se conserva el ánimo y la disposición de trabajar por el bienestar colectivo, procurando la ayuda mutua, que sirva como acicate para fortalecer los lazos de 
solidaridad, unidad y fraternidad; donde los individuos se abran a los otros como pares, que no solo los cuestionen sino que también los complementen.

Por otra parte, el cuidado de sí no implica un desconocimiento de las reglas y de las coacciones sociales, sino que, por el contrario, gestiona la posibilidad de someterse a las mismas, sin perder el ejercicio de la autonomía y la libertad individual, puesto que en los espacios de interacción social es comprensible que deben existir reglas, y que estas han sido constituidas para ser asumidas por todos los individuos, con el fin de favorecer el diálogo y la integración. En últimas, ni el cuidado de sí es una propuesta que de origen al narcicismo contemporáneo, ni tampoco plantea una pérdida de la identidad y, mucho menos, de la integridad física del individuo, pues de ninguna manera se puede compartir la idea de que la persona tenga que "matarse" con el fin de favorecer a los otros.

Teniendo como referentes teóricos a Michel Foucault e Irene Comins se ha querido exponer una antropología centrada en el cuidado, tanto de sí, como de los otros. Una antropología diferente a la expuesta en el primer capítulo, que tiene unos rasgos diferenciadores, que pueden ser sintetizados en los siguientes aspectos: el cuidado de sí, implica un conocimiento propio, un reconocimiento del otro, y un afán por comprender su situación, por ser empáticos, combatiendo la exclusión y la segregación de todo tipo. El cuidado de sí exige trabajo y tiempo, pues no se puede cuidar al otro o cuidarnos, si no disponemos de tiempo.

Ahora bien, es preciso apostarle a este tipo de antropología como sustento de la formación desde el hogar, en el colegio y la sociedad en general, donde el ser humano sea autónomo, crítico, creativo y reflexivo de lo que le acontece en su devenir cotidiano, y donde la relación con uno mismo sea una relación concreta:

Una relación que permite gozar de uno mismo como de una cosa que está a la vez en posesión de uno y ante sus ojos [...] es 
la única parte de nuestra vida que es sagrada e inviolable, que ha escapado a todos los azares humanos, que está sustraída al imperio de la fortuna, que la pobreza no trastorna, ni el temor, ni la incursión de las enfermedades; ésta no puede ser perturbada ni arrebatada; perpetua y serena es su posesión. Y la experiencia de uno mismo que se forma en esta posesión no es simplemente la de una fuerza domeñada, o de una soberanía ejercida sobre un poder listo a rebelarse; es la de un placer que toma uno en sí mismo. Aquel que ha llegado a tener finalmente acceso a sí mismo es para sí mismo un objeto de placer. (Foucault, 1987, p. 65)

Una antropología del cuidado involucra necesariamente una actividad, una atención, una elección de conocimientos primordiales para llevar una vida saludable, una vida buena, con sentido, con propósito, donde se promueva la autodeterminación, y se denuncie la vida consumista que segrega, somete y aliena.

Los principales interrogantes que intenta responder la antropología del cuidado gravitan en torno al cómo debemos conducirnos y cómo lograr una vida buena. La búsqueda de las respuestas a estos interrogantes nos lleva necesariamente a un sujeto de acción, un individuo que se ocupe de sí mismo, y se preocupe por su entorno social, puesto que al conducirse bien y al buscar vivir una vida buena, se compenetra de forma innegable con el otro en la construcción mutua.

En una antropología del cuidado, el individuo busca constituirse y transformarse a sí mismo en un sujeto ético y político que se sabe conducir y que pretende, como sujeto de acción, coadyuvar a sus pares con el propósito de que se desarrollen también como sujetos éticos y políticos. El cultivo de sí describe una actividad permanente que implica atención, conocimiento y búsqueda constante en bien de su propia formación y de los otros. 


\section{Aspectos constitutivos de los individuos como sujetos morales}

El profesor Cubides Cipagauta, estudioso de Foucault, considera que el pensador francés recapitula en su propuesta filosófica del cuidado cuatro aspectos relevantes en torno a la manera como el individuo termina estableciéndose en un sujeto moral, responsable de sus actuaciones. Estos cuatro aspectos resultan interesantes a la hora de edificar y apostarle a una antropología del cuidado, según Cubides:

Foucault retoma los cuatro aspectos de la reflexión filosófica que se han conservado a lo largo del tiempo configurando ámbitos específicos de análisis sobre la manera como el individuo se constituye a sí mismo como sujeto moral de sus propias acciones: $1^{\circ}$ La determinación de la sustancia ética, es decir, aquello que es la materia principal del juicio y conducta ética (ontología); $2^{\circ} \mathrm{El}$ modo de sujeción, esto es, la manera como se incita o invita a la gente a dar cuenta de sus obligaciones morales, estableciendo determinada relación con la regla (la deontología); $3^{\circ}$ Las formas de elaboración o trabajo ético que hacemos sobre nosotros mismos, o los medios como cambiamos para convertirnos en sujetos éticos (ascética); $4^{\circ}$ La clase de ser al cual aspiramos cuando nos comportamos de manera moral (teleología). (Cubides Cipagauta, 2006, p. 20)

En relación con el primer aspecto, que corresponde al nivel ontológico, podemos aseverar que el individuo debe procurar mantener el equilibrio corporal, donde se deben evitar tanto los excesos en el cuidado físico, como en la exigencia corporal. Con un refrán popular podemos sintetizar este aspecto: ni tanto que queme al santo, ni tan poco que no lo alumbre. Se trata de un ejercicio de prudencia, puesto que, "el sujeto prudente debe ser 
capaz de dominar las fuerzas que se desencadenan en él y hacer de su vida una obra que supere su pasajera existencia" (Cubides Cipagauta, 2006, p. 22).

En cuanto al segundo aspecto, el deontológico, podemos asegurar que aquí cabe preguntarse por el principio al cual se debe remitir el ser humano para ordenar y moderar la acción placentera. En este sentido, se puede afirmar que el principio con el cual debemos comprometernos desde la propuesta antropológica que defendemos, gravita en torno al cuidado de uno mismo, que desemboca necesariamente en el cuidado de los otros.

En cuanto al tercer aspecto, el ascético, lo podemos ver relacionado con el placer sexual, donde se reitera la necesidad del autocontrol, puesto que tanto hombres como mujeres están llamados a ejercer su sexualidad en forma humana, que construya y consolide la unión mutua, mas no para constituirse simplemente como objetos de placer que terminan deshumanizándose y cayendo en el vacío y la decepción. Frente a este aspecto ascético, afirma el profesor Cubides:

En la época de la Grecia Clásica, la ascética estaba completamente vinculada al cultivo de una vida virtuosa. Respecto del uso de los placeres, lo que demanda es una práctica de trabajo y un control del individuo sobre sí mismo para dominarlos, junto con sus deseos, en la búsqueda de la temperancia y de un estado sólido y estable de autodominio del sujeto. (Cubides Cipagauta, 2006, p. 27)

Para una antropología del cuidado este aspecto es supremamente importante, pues, el cultivo de una vida sana, íntegra, inmaculada, regulando lo instintivo y apetitivo, lleva a una vida buena, y a una autodeterminación de los sujetos. Al elegir unos ejercicios encaminados a alcanzar la autonomía, se puede lograr una especie de ascetismo, de purificación, donde finalmente se 
logre el dominio de las pasiones, y el gobierno de sí, como lo manifiesta Cubides:

El cuidado de sí mismo implica una actividad, una atención, la elección de conocimientos importantes para vivir de cierto modo y unas técnicas adquiridas mediante el ejercicio de uno mismo sobre uno mismo (askesis). Todo lo cual supone otro tipo de constitución del sujeto, en el que éste logra gobernarse a sí mismo (autoconstitución), opuesto a las artes de gobierno que se apropian de la vida del individuo y lo colocan en una situación de sometimiento, pretendiendo determinar su modo de vivir con el pretexto de aliviar su cuidado de sí (biopolítica y biopoder). De este modo, la ética, el ethos, entendido como una gestión de la vida susceptible de ser planificada y reflexionada por el individuo, se constituiría en el principal medio de que dispone el individuo para resistir el poder dominante, dándole la posibilidad de modificar las situaciones de sometimiento. (Cubides Cipagauta, 2006, p. 71)

En una antropología del cuidado, el individuo se erige, entonces, como un sujeto autónomo, de acciones independientes de los dictámenes de los gobernantes de turno, y procura ejercer su libertad, zafándose del yugo de los que ostentan el poder.

En lo relacionado con el cuarto aspecto, el teleológico, se busca atender al interrogante sobre el ideal de individuo al que aspiramos cuando actuamos correctamente. Este factor también es muy importante en nuestra propuesta antropológica, puesto que pretendemos que los individuos que emerjan de una sociedad anclada en el cuidado de sí, sean seres virtuosos y que, a su vez, coadyuven en el fortalecimiento de gobiernos virtuosos, donde el bienestar colectivo sea la principal preocupación de sus orientaciones.

Uno de los principales fines de una antropología del cuidado radica en desarrollar actitudes experimentales, donde se detecten los puntos neurálgicos que hay que intervenir para lograr un 
cambio que posibilite una vida mejor para todos; donde se piense en el medio ambiente, en la inclusión de aquellos grupos minoritarios excluidos (LGTBI, desempleados, afros e indigentes, entre otros), y donde el compromiso se manifieste en calidad de vida para todos y no para solo unos pocos.

Se pretende que con la promoción de una antropología fundada en la inquietud de sí, el cuidado de sí, el conocimiento de sí, se dejen sentadas las bases para una propuesta que se aleje por una parte, del individualismo extremo, y por la otra, de un tribalismo que raya en el gueto. En nuestra concepción antropológica se propende por cultivar en los individuos sentimientos de solidaridad, y que se susciten transformaciones sociales, donde aflore el conflicto como elemento innato de los individuos, y sea encausado mediante el diálogo hacia proyectos comunes. Se trata de una propuesta donde el tiempo sea un factor clave para cuidar de sí y de los demás, y de la misma forma, donde los individuos puedan experimentar su libertad:

La gente necesita tiempo libre para experimentar la libertad. No pueden generar o ser regenerativos sin descansar, ni tampoco pueden estar abiertos a recibir lo que es generosidad hacia ellos si están atrapados en un perpetuo apuro [...] Hay que tener la valentía de decir "No" y descansar, discernir lo que se necesita y desea. (Vardey, 2012, pp. 46-47)

En esta antropología del cuidado se propende por la promoción de lazos de fraternidad, más allá de los modelos neoliberales, que suscitan ideales de individuos exitosos en sociedades colapsadas. Se trata de lograr la constitución de personas que se ocupen de sí, sin olvidarse de los otros, y que, a su vez, le ayudan a otros a configurarse como tales. De esta manera, en la propuesta antropológica que sustentamos se ve claramente el interés porque las personas sean virtuosas, autónomas, cooperativas, y donde el dinero sea un medio y no un fin, y donde el trabajo posibilite el descanso, la contemplación, la salud, el ahorro y el bienestar en general 